\title{
Ultrasonic-microwave synergistic extraction of paprika pigment
}

\author{
Min Pang ${ }^{1, *}$, Qian Liu ${ }^{1}$, Yan li Yu ${ }^{1}$ and Song ling Cai ${ }^{1}$ \\ ${ }^{1}$ Food quality and safety Department, Shanghai Sanda University, China
}

\begin{abstract}
Paprika was soaked in n-hexane to extract paprika pigment by using ultrasonic and microwave assisted extraction (UMAE). The effects of different operating variables were investigated and the extraction condition was optimized through orthogonal design: ultrasonic power of $50 \mathrm{w}$, microwave power of $240 \mathrm{w}$, powder-solvent ratio of 1: $25(\mathrm{~g} / \mathrm{mL})$, microwave time of $600 \mathrm{~s}$, paprika particle size of $60 \mathrm{mesh}$. At these conditions, the color value of 147 of paprika pigment was reached. Compared with the conventional water bath extraction method, UMAE has the advantages of shorter extraction time and higher efficiency, which may be related to the effect of UMAE on destroying the cellular structure of paprika.
\end{abstract}

\section{Introduction}

As a natural and safe colorant, paprika pigment is widely used by the food industry to provide or reinforce color in foodstuffs ${ }^{[1][2]}$. Paprika pigment has a great number of carotenoids, of which capsorubin and capsanthin are the main components contributing up to $60 \%-85 \%$ of the total amount ${ }^{[3]}$. Except for its coloration used in food, paprika pigment also has many other bioactivities such as anti-oxidant ${ }^{[4][5]}$, anti-tumor ${ }^{[6]}{ }^{[7]}$ and anti-adipogenic ${ }^{[8]}$. Extraction of paprika pigment is an important step for its application and further research, some authors have exploited water bath extraction ${ }^{[9][10]}$, ultrasonic-assisted extraction $^{[11][12]}$ microwave-assisted extraction ${ }^{[13]}$, supercritical $\mathrm{CO}_{2}$ extraction ${ }^{[14][15]}$, and subcritical water extraction ${ }^{[16]}$ as methods for extraction of paprika pigment. However, the current research focuses on the single use of ultrasound or microwave in assisted extraction, little study has been done on ultrasoundmicrowave synergistically assisted extraction of paprika pigment. In order to achieve fast and efficient extraction technique, ultrasonic-microwave synergistic assisted extraction was carried out to explore the extraction of paprika pigment in this paper; meanwhile the operating conditions were studied by orthogonal analysis to determine their influence on the color value of paprika pigment.

\section{Experimental}

\subsection{Material and Instruments}

Paprika was purchased from local market; n-hexane and acetone of analytical grade were commercially supplied by China Pharmaceutical Group Co., Ltd. An UMSE apparatus (CW-2000, Shanghai Xintuo Microwave Instrument Co. Ltd, China) with microwave power of $10 \mathrm{w}-800 \mathrm{w}$ and an ultrasonic transducer with a fixed power of 50w was used in extraction; UV-vis spectrophotometer(UV-2000, Shanghai Yonike Co., Ltd).

\subsection{Experimental method}

\subsubsection{Ultrasonic-microwave synergistic assisted extraction of paprika pigment}

The paprika were grinded and sieved into particles of different sizes after being dried at $60^{\circ} \mathrm{C}$ for $4 \mathrm{~h}$, then $3 \mathrm{~g}$ of the pretreated dried powder was transferred into a beaker, n-hexane was added into the beaker, and then the beaker was transferred into the UMSE apparatus connected with a condensing tube and the extraction was carried out under varied microwave power for different times. As operating variables, paprika particle size (20mesh, 40mesh, 60mesh, 80mesh, 100mesh), microwave power $(80 \mathrm{w}, 120 \mathrm{w}, 160 \mathrm{w}, 200 \mathrm{w}, 240 \mathrm{w})$, UMAE time (120s, 240s, 360s, 480s, 600s) and powder-solvent ratio $(1: 10,1: 15,1: 20,1: 25,1: 30)$ were selected to obtain the most suitable extraction process.

\subsubsection{Optimization of paprika pigment extraction}

The extraction parameters were optimized by orthogonal design. On the basis of the preliminary range of extraction variables, a $\mathrm{L}_{9}(3)^{4}$ (four-factor- three-level) orthogonal design was adopted as table 1. Four extraction variables considered were A (powder-solvent ratio), B (microwave power), C (extraction time), and D (paprika particle size). The color value was used as the dependent variable.

Table 1. Factors and levels of orthogonal design

\begin{tabular}{ccccc}
\hline & \multicolumn{4}{c}{ Variable factor } \\
\cline { 2 - 5 } el & $\mathrm{A}$ & $\mathrm{B}$ & $\mathrm{C}$ & $\mathrm{D}$ \\
& powder- & microwa & extractio & paprika \\
& solvent ratio & ve power & n time & $\begin{array}{c}\text { particle } \\
\text { size(mes }\end{array}$ \\
\hline
\end{tabular}




\begin{tabular}{ccccc}
\hline & $(\mathrm{g} / \mathrm{mL})$ & $(\mathrm{w})$ & $(\mathrm{s})$ & $\mathrm{h})$ \\
\hline 1 & $1: 20$ & 160 & 360 & 60 \\
2 & $1: 25$ & 200 & 480 & 80 \\
3 & $1: 30$ & 240 & 600 & 100 \\
\hline
\end{tabular}

\subsubsection{Coloring capacity analysis}

Color value unit is an important indicator for evaluating the quality of paprika pigment, and it is positively correlated with the content of paprika pigment. The color value is expressed as $E_{1 \mathrm{~cm}}^{1 \%} 460 \mathrm{~nm}$ according to GB1886.34-2015. A known amount of sample $(0.4 \mathrm{~g} \sim 1.0$ $\mathrm{g})$ is transferred to a $100 \mathrm{~mL}$ volumetric flask and diluted with acetone. After-wards, an aliquot of $1 \mathrm{~mL}$ of this sample is transferred into another $100 \mathrm{~mL}$ volumetric flask and diluted to volume with acetone. After shaking the dilution, its absorption was measured using a UV-vis spectrophotometer. The calculation formula is as follows:

$$
E_{1 \mathrm{~cm}}^{1 \%} 460 \mathrm{~nm}=\frac{\mathrm{A} \times \mathrm{f}}{100 \times \mathrm{m}}
$$

Where " $A$ " represents the absorbance of the test sample at 460nm; "f" represents the dilution factor; " $\mathrm{m}$ " represents the mass of the sample in grams $(\mathrm{g})$, and 100 is the conversion factor.

\section{Results and discussion}

\subsection{Effect of paprika particle size on color value}

The size and structure of the paprika particles are important factors influencing the extraction process. Whereas big mesh imply small paprika particle size, Fig. 1 shows that when the particle size of the paprika is from 20 mesh to 80 mesh, the color value increases with the decreasing particle size, but the color value is reduced when the paprika powder is 100 mesh. The smaller the particle size is, the larger the surface area in contact with the solvent is, which contribute to the increase in the dissolution of paprika pigment. However, when the particle size is too small, it will result in the increase of viscosity and the enhanced solubility of impurities ${ }^{[17]}$, as a consequence, leading to the reduction of paprika pigment dissolution and the difficulty of filtration. Therefore, 80 mesh was selected.

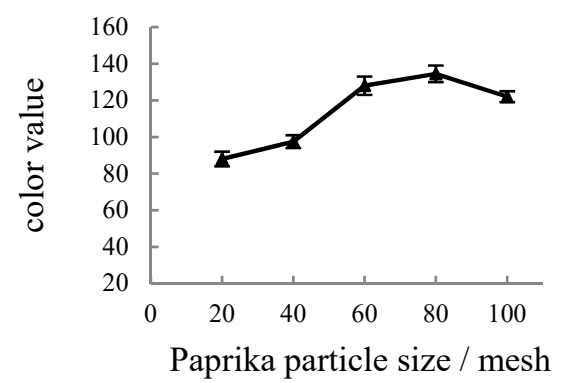

Fig.1 Effect of paprika particle size on color value

\subsection{Effect of powder-solvent ratio on color value}

The process of extracting paprika pigment from paprika powder is a solid-liquid mass transfer process and the concentration difference between intracellular and extracellular is the driving force of this process ${ }^{[18]}$. The effect of different powder-solvent ratio on the color value is shown in Fig.2. As can be seen, with the increase of powder-solvent ratio, the color value increases first and then keeps stable. When the powder -solvent ratio is small, the concentration of paprika pigment in the solution has little difference from that in the cell, which makes it difficult to transfer paprika pigment from the cell of paprika to the solution. Attending to this indication, large powder-solvent ratio can increase the dissolution rate of paprika pigment. However, considering that the more solvent is used, the higher the cost will be, so powder-solvent ratio is 1:25.

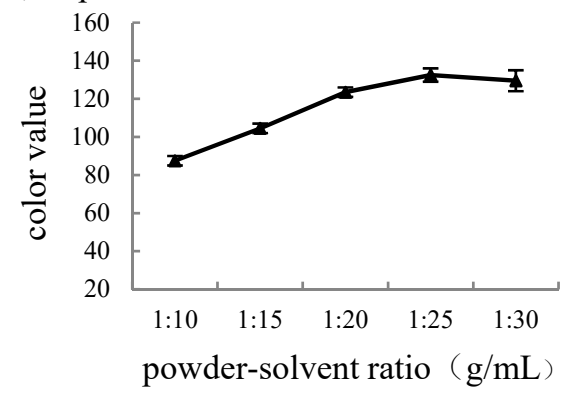

Fig.2 Effect of powder-solvent ratio on color value

\subsection{Effect of microwave power on color value}

Microwave power will affect the extraction temperature, thus affecting the dissolution and diffusion of the paprika pigment. As can be seen from Fig.3, with the increase of microwave power, the color value of paprika pigment increases first and then decreases, maximum color value was obtained when the microwave power is $200 \mathrm{w}$. This can be explained as follows: in the same time, the higher the microwave power is, the more microwave energy was absorbed by extraction system, which raised the system temperature and contributed to the increase of paprika pigment transfer from the inner part of paprika particles to the solution. However, excessive power may cause the destruction of paprika pigment and increase the operating load of equipment, so choose the microwave power of $200 \mathrm{w}$.

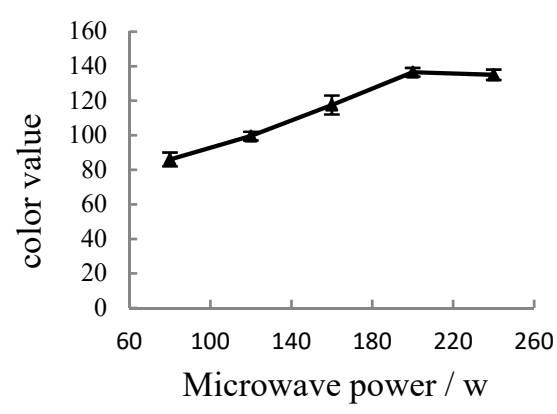

Fig.3 Effect of microwave power on color value

\subsection{Effect of UMAE time on color value}

For the extraction process, the interaction between extraction rate and extraction time is the reason affecting the quality of paprika pigment. As listed in Fig.4, with the increase of extraction time, the color value of paprika 
pigment increased gradually. Fix the microwave and ultrasonic power, the absorption of microwave and ultrasonic energy increased with the increase of extraction time, causing the temperature of extraction system continue to rise and accelerating the diffusion rate of paprika pigment, but when the diffusion reached equilibrium, the dissolution of paprika pigment is no longer increased even if the extraction time extended. Therefore, the extraction time is $480 \mathrm{~s}$.

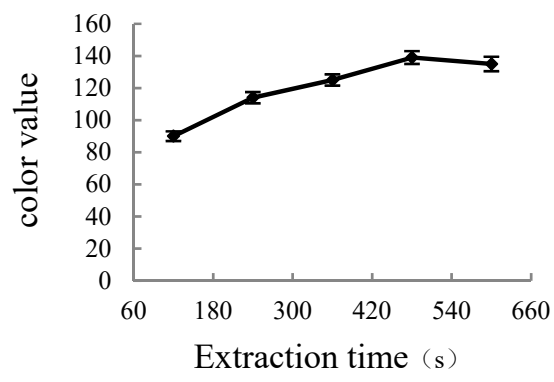

Fig.4 Effect of UMAE time on color value

\subsection{Orthogonal design results and analysis}

When the influence of operating variables is analyzed, quality of extracted paprika pigment expressed as color value was taken into account. According to the $R$ values, table 2 previously pointed out the main effects of the analyzed factors on the color value decreases in the order :B $>\mathrm{A}>\mathrm{C}>\mathrm{D}$, microwave power was found to be the most important determinant of color value. In other words, the maximum color value was obtained when the operating conditions were $\mathrm{B}_{3} \mathrm{~A}_{2} \mathrm{C}_{3} \mathrm{D}_{1}$, that is, microwave power 240w, powder-solvent ratio 1:25 (g/mL), extraction time $600 \mathrm{~s}$ and paprika powder 60 mesh.

\subsection{Verification test}

According to the optimum extraction condition $\mathrm{B}_{3} \mathrm{~A}_{2} \mathrm{C}_{3} \mathrm{D}_{1}$, three parallel experiments were carried out. The average color value of paprika pigment was 147 , which was higher than that of single factor group and orthogonal experiment group.

Table 2. Orthogonal design and experimental results of ultrasonic-microwave synergistic extraction

\begin{tabular}{cccccc}
\hline Experimental number & A & B & C & D & Color value \\
\hline 1 & 1 & 1 & 1 & 1 & 112 \\
2 & 1 & 2 & 2 & 2 & 123 \\
3 & 1 & 3 & 3 & 3 & 139 \\
4 & 2 & 1 & 2 & 3 & 115 \\
5 & 2 & 2 & 3 & 1 & 136 \\
6 & 2 & 3 & 1 & 2 & 142 \\
7 & 3 & 1 & 3 & 2 & 133 \\
8 & 3 & 2 & 1 & 3 & 140 \\
9 & 3 & 3 & 2 & 1 & 129.333 \\
$\mathrm{~K}_{1}$ & 124.667 & 115.000 & 129.000 & 127.667 & \\
$\mathrm{~K}_{2}$ & 131.000 & 130.6670 & 126.000 & 129.000 & \\
$\mathrm{~K}_{3}$ & 130.333 & 140.333 & 131.000 & 1.666 & \\
$\mathrm{R}$ & 6.333 & 25.333 & 5.000 & & \\
\hline
\end{tabular}

$\mathrm{R}$ refers to the result of extreme analysis

\section{Comparison of methods}

Choosing the optimum extraction conditions respectively, the effects of ultrasonic-microwave assisted extraction and traditional water bath extraction on the color value of paprika pigment were compared. As the results in table 3 shown: the color value of paprika pigment extracted by ultrasonic-microwave assisted extraction was147, which was higher than 124 by traditional extraction method, and the extraction time was also significantly shortened. The reason was given as followings: ultrasonic-microwave assisted extraction makes full use of the mechanical vibration and cavitation effect of ultrasonic wave to destroy paprika cellular structure effectively, contributing to the increase of paprika pigment transfer from the inner part of paprika particles to the solvent. Moreover, microwave technology can make the target molecules in the sample align directionally under the action of microwave electromagnetic field, and high-frequency oscillation occurs with the alternate change of microwave electromagnetic field, thus accelerating the paprika pigment from solid phase into solvent phase and shortening the processing time.

Table 3. Comparison of different extraction methods

\begin{tabular}{lccccccc}
\hline Extraction method & $\begin{array}{l}\text { ultrasonic } \\
\text { power }\end{array}$ & $\begin{array}{l}\text { microwave } \\
\text { power }\end{array}$ & $\begin{array}{l}\text { extraction } \\
\text { temperature }\end{array}$ & $\begin{array}{l}\text { powder-solven } \\
\text { t ratio }\end{array}$ & $\begin{array}{l}\text { extraction } \\
\text { time }\end{array}$ & $\begin{array}{l}\text { paprika } \\
\text { particle } \\
\text { size }\end{array}$ & $\begin{array}{l}\text { color } \\
\text { value }\end{array}$ \\
\hline $\begin{array}{l}\text { Traditional water bath } \\
\text { extraction }\end{array}$ & - & - & $70^{\circ} \mathrm{C}$ & $1: 25(\mathrm{~g} / \mathrm{mL})$ & $100 \mathrm{~min}$ & $60 \mathrm{mesh}$ & 124 \\
Ultrasonic-microwave & $50 \mathrm{w}$ & $240 \mathrm{w}$ & - & $1: 25(\mathrm{~g} / \mathrm{mL})$ & $600 \mathrm{~s}$ & $60 \mathrm{mesh}$ & 147 \\
\hline
\end{tabular}


assisted extraction

\section{Conclusion}

The optimum extraction conditions of paprika pigment were determined by single factor experiment and orthogonal design. The extraction solvent was n-hexane, $50 \mathrm{w}$ ultrasonic power, $240 \mathrm{w}$ microwave power, 1:25 powder-solvent ratio $(\mathrm{g} / \mathrm{mL}), 600 \mathrm{~s}$ extraction time, 60 mesh of paprika particle size, by the above process, the color value of paprika pigment was 147 .

Compared with the traditional extraction methods, ultrasonic-microwave assisted extraction can improve the color value of paprika pigment and shorten the extraction time obviously. More importantly, it can avoid the decomposition of active substances caused by long-time extraction under high temperature and pressure. The results obtained in this work throw light on the extraction of active substances from natural plants and provide valuable information to pre-treatment in analysis and detection of paprika pigment.

\section{References}

1. Guoqing Huang, Zhen zhen Xu, et al. Study on the preparation of $\mathrm{O} / \mathrm{W}$ Paprika red pigment emulsion. China food additives, 1 (2016).

2. Janiszewska-Turak E, Pisarska A, Królczyk J B. Natural food pigments application in food products. 10(2016,).

3. Weissenberg, M. Isocratic non-aqueous reversed-phase high-performance liquid chromatographic separation of capsanthin and capsorubin in red peppers (Capsicum annuum L.), paprika and oleoresin. J of Chromatography $A \mathbf{7 5 7}$ (1997).

4. Mendozasánchez, Liliana G, et al. Propiedades fisicoquímicasy antioxidant esdel chile jalapeño (Capsicum annuum var. annuum) durante almacenamiento. Revista Chapingo Serie Horticultura 21(2015).

5. W Warsi, A Guntarti. Antioxidant activity of methanolic extract from yellow paprika (Capsicum annuum, L.) by DPPH radical scavenging method. Pharmaciana,7(2017)

6. Zhang, Xia, W. E. Zhao, and L. Hu. Carotenoids inhibit proliferation and regulate expression of peroxisome proliferators-activated receptor gamma $(\mathrm{PPAR} \gamma)$ in K562 cancer cells. Archives of
Biochemistry \& Biophysics 512(2011).

7. Molnár, J, et al. Putative supramolecular complexes formed by carotenoids and xanthophylls with ascorbic acid to reverse multidrug resistance in cancer cells. Anticancer Research 32(2012).

8. Han, Byunghoon. Functional food and pharmaceutical compositions for anti-obesity comprising capsanthin and fatty-acyl ester of capsanthin having anti-adipogenic activity. (2012).

9. Yawen Wei, Lingxia Le. Research Progress on Extraction Methods and Application of Capsanthin. China Condiment, 8(2017).

10. Santamaría, R. I, et al. Selective enzyme-mediated extraction of capsaicinoids and carotenoids from chili guajillo puya (Capsicum annuum L.) using ethanol as solvent. Journal of Agricultural \& Food Chemistry 48 (2000).

11. Jianglong Wang. Study on Extraction of capsicum red pigment from red pepper. Shihezi University, (2015).

12. Fernández-Ronco, María P., et al. Extraction of Capsicum annuum Oleoresin by Maceration and Ultrasound-Assisted Extraction: Influence of Parameters and Process Modeling. Journal of Food Process Engineering 36 (2013).

13. Liye Liu, Fangli Zhong. Study on Extraction of Capsanthin by Microwave Assisted Method. Liaoning Chemical Industry, 11 (2015).

14. Fernández-Ronco, M. P., et al. Supercritical fluid fractionation of liquid oleoresin capsicum: Statistical analysis and solubility parameters. Journal of Supercritical Fluids 54 (2010).

15. Aguiar, Ana Carolina De, et al. Encapsulation of pepper oleoresin by supercritical fluid extraction of emulsions. Journal of Supercritical Fluids 112(2016).

16. WANG Hong, XU Man xu. Optimization of Extraction TechnoIogy for Red Pigment of Capsicum by SubcriticaI Water. China Condiment, 12(2016).

17. Shufen li, zhognyi jiang. Separation engineering of pharmaceutical industry. Chemical Industry Press, (2004).

18. Zhaoxia wang. Separation of capsicum red pigment from capsaicin and development of technological process. Lanzhou University,(2008 